\title{
О ТЕЛОМЕРИЗАЦИИ 4-ХЛОР-2-ПЕНТЕНА С АРИЛЗАМЕЩЕННЫМИ ЭТЕНА
}

В ['] установлено образование 6-бром-4-метил-6-фенил-2-гексена теломеризацией 4-бром-2-пентена со стиролом в присутствии $\mathrm{SnCl}_{4}$. Данная реакция подвергнута нами подробному исследованию при помощи ГЖХ галогенпроизводных $\left.{ }^{2}\right]$ и спектрометрии ПМР. Изучены качественный и количественный составы теломеров 4-хлор-2-пентена с различными арилзамещенными этена и влияние на них соотношения телоген : таксоген $(1: 2,1: 1,2: 1)$. Для сведения к минимуму влияния физических свойств среды исходные реакционные смеси с различным содержанием телогена и таксогена составляли путем добавления к реагентам растворителей $-1,2$-дихлорэтана и $\boldsymbol{H}$-гексана в соотношениях, позволяющих сохранить плотность, вязкость и диэлектрическую проницаемость среды в узких пределах. На основании полученных данных можно заключить, что избыток телогена на выход моноаддуктов существенно не влияет, избыток таксогена увеличивает количество высших теломеров. Результаты исследования приведены в табл. 1. Введение заместителя - метильной группы - в таксоген в $M$-, $n$-положение фенильного кольца приводит к снижению выхода первых теломергомологов (табл. 1).

Таблица 1

Характеристика реакции теломеризации 4-хлор-2-пентена (телоген) с арилзамещенными этена. Катализатор - безводное хлорное олово. Температура реакции $0-3 \pm 1,5^{\circ} \mathrm{C}$

\begin{tabular}{|c|c|c|c|c|c|c|c|c|c|}
\hline \multirow{2}{*}{$\begin{array}{l}\text { Арилзаме- } \\
\text { щенный } \\
\text { этен } \\
\text { (таксоген) }\end{array}$} & \multicolumn{2}{|c|}{$\begin{array}{c}\text { Растворители в } \\
\text { реакционной } \\
\text { смеси, } \\
\text { г-моль/л } \\
\end{array}$} & \multirow{2}{*}{ 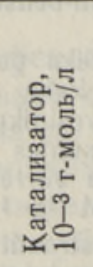 } & \multirow[b]{2}{*}{ 这 } & \multicolumn{2}{|c|}{$\begin{array}{c}\text { Изменение кон- } \\
\text { центрации } \\
\text { реагентов, } \\
\text { г-моль/л }\end{array}$} & \multirow{2}{*}{ 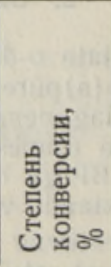 } & \multicolumn{2}{|c|}{$\begin{array}{c}\text { Выход тело- } \\
\text { мергомологов } \\
\text { от тело- } \\
\text { мера, \% }\end{array}$} \\
\hline & $\begin{array}{c}\text { 1,2-ди- } \\
\text { хлор- } \\
\text { этан }\end{array}$ & $\begin{array}{l}\mu \text {-reк- } \\
\text { сан }\end{array}$ & & & $\begin{array}{c}\text { тело- } \\
\text { ген }\end{array}$ & $\begin{array}{c}\text { таксо- } \\
\text { ген }\end{array}$ & & $n=1$ & $n=2,3$ \\
\hline тирол & 3,54 & 2,62 & 1 & $\begin{array}{r}0 \\
4 \\
35 \\
125\end{array}$ & $\begin{array}{l}1,68 \\
1,27 \\
0,84 \\
0,33\end{array}$ & $\begin{array}{l}1,68 \\
1,15 \\
0,64 \\
0,14\end{array}$ & $\begin{array}{c}0 \\
27,82 \\
55,96 \\
85,96\end{array}$ & $\begin{array}{c}0 \\
84,96 \\
87,34 \\
88,65\end{array}$ & $\begin{array}{c}0 \\
15,04 \\
12,66 \\
11,35\end{array}$ \\
\hline Стирол & 3,56 & 1,11 & 0,9 & $\begin{array}{r}0 \\
4 \\
11 \\
115\end{array}$ & $\begin{array}{l}2,22 \\
1,86 \\
1,42 \\
1,26\end{array}$ & $\begin{array}{l}1,11 \\
0,62 \\
0,15 \\
0,02\end{array}$ & $\begin{array}{c}0 \\
25,72 \\
53,14 \\
61,57\end{array}$ & $\begin{array}{c}0 \\
85,71 \\
85,52 \\
87,91\end{array}$ & $\begin{array}{c}0 \\
14,29 \\
14,48 \\
12,09\end{array}$ \\
\hline Стирол & 3,61 & 2,46 & 1,8 & $\begin{array}{r}0 \\
3 \\
15\end{array}$ & $\begin{array}{l}1,14 \\
0,75 \\
0,17\end{array}$ & $\begin{array}{l}2,27 \\
1,68 \\
1,00\end{array}$ & $\begin{array}{c}0 \\
29,21 \\
66,11\end{array}$ & $\begin{array}{c}0 \\
77,52 \\
73,85\end{array}$ & $\begin{array}{c}0 \\
22,48 \\
26,15\end{array}$ \\
\hline $\begin{array}{l}\text { l-, } n \text {-Метил- } \\
\text { стирол }\end{array}$ & 3,60 & 2,48 & 1,3 & $\begin{array}{r}0 \\
8 \\
16 \\
49\end{array}$ & $\begin{array}{l}1,61 \\
1,34 \\
0,94 \\
0,47\end{array}$ & $\begin{array}{l}1,59 \\
1,19 \\
0,64 \\
0,08\end{array}$ & $\begin{array}{c}0 \\
21,39 \\
51,30 \\
83,51\end{array}$ & $\begin{array}{c}0 \\
65,69 \\
72,59 \\
68,95\end{array}$ & $\begin{array}{c}0 \\
34,41 \\
27,41 \\
31,05\end{array}$ \\
\hline
\end{tabular}


Физико-химические константы соединений, синнтезированных теломеризацией 4-хлор-2-пентена с арилзамещенными этена

\begin{tabular}{|c|c|c|c|c|c|c|}
\hline $\begin{array}{l}\text { Ho- } \\
\text { мep }\end{array}$ & Соединение & $\underset{\%}{\text { Выход, }}$ & $\begin{array}{l}\text { T. кип., }{ }^{\circ} \mathrm{C} \\
\text { (при } 3 \text { мм } \\
\text { рт. ст.) }\end{array}$ & $d_{6}^{20}$ & $n_{D}^{20}$ & $\begin{array}{c}\text { Чнсто- } \\
\text { та по } \\
\text { ГЖХ, } \\
\%\end{array}$ \\
\hline I & 6-Хлор-4-мет & & & & & \\
\hline & 2 -гексен & 88,6 & $120-122$ & 0,9919 & 1,5171 & 99,3 \\
\hline II & $\begin{array}{l}\text { 6-Хлор-4-метил-6-метил- } \\
\text { фенил-2-гексен }\end{array}$ & 72,6 & $138-145$ & 0,9814 & 1,5175 & 99,1 \\
\hline III & 3-Метил-1-фенил-4-гексен-1-ол & 85,3 & $112-115$ & 0,9545 & 1,5154 & 99,7 \\
\hline IV & $\begin{array}{l}\text { 3-Метил-1-метилфенил-4-гексен- } \\
\text { 1-ол }\end{array}$ & 82,1 & 124 & 0,9476 & & 98,6 \\
\hline V & 3-Метил-1-фенил-4-гексен-1-он & 81,5 & $116-118$ & 0,9703 & 1,5220 & 99,9 \\
\hline VI & $\begin{array}{l}\text { 3-Метил-1-метилфенил-4-гексен- } \\
\text { 1-он }\end{array}$ & 72,3 & $125-133$ & 0,9787 & 1,5231 & 98,8 \\
\hline
\end{tabular}

Известно применение в качестве душистых веществ 5-метил-1-фенил4-гексен-1-она и его гомологов, обладающих запахом свежей зелени $\left[{ }^{3,4}\right]$. Из синтезированных 6-хлор-4-метил-6-фенил-2-гексена (I) и 6-хлор-4метил-6-метилфенил-2-гексена (II) нами получены 3-метил-1-фенил-4-гексен-1-ол (III) и 3-метил-1-метилфенил-4-гексен-1-ол (IV). Окисление полученных спиртов (III) и (IV) хромовой смесью приводит к образованию 3-метил-1-фенил-4-гексен-1-она (V) и 3-метил-1-метилфенил-4-гексен-1она (VI). Характеристика синтезированных соединений приведена в табл. 2. Химическое строение синтезированных соединений определено методами их получения и спектрами ПМР (табл. 3). Из данных табл. 3 следует, что в спектрах полученных веществ сохраняются химические сдвиги протонов исходного телогена - 4-хлор-2-пентена и исходных таксогенов - фенилэтена, $M$-, $n$-метилфенилэтена (см. сигналы протонов групп: $\mathrm{CH}_{3}-\mathrm{C}-,-\mathrm{CH}=\mathrm{CH}-,-\mathrm{CH}-\mathrm{C}-,-\mathrm{CH}_{2}-,-\mathrm{CH}-\mathrm{Cl},-\mathrm{CH}-$ $-\mathrm{O}-, \mathrm{C}_{6} \mathrm{H}_{5}-,-\mathrm{C}_{6} \mathrm{H}_{4}-\mathrm{CH}_{3}$ ), что позволяет с большой вероятностью подтвердить предложенные структуры. Соединения (III) и (IV) обладают запахом зелени с различными оттенками и заявлены в качестве синтетических душистых веществ $\left[{ }^{5,6}\right]$.

\section{Экспериментальная часть}

ГЖХ-анализ синтезированных окси- и оксопроизводных проводили на хроматографе «Хром- $»$, с колонкой $(l=5$ м, $d=4,5$ мм), заполненной этиленгликольадипинатом $(3 \%)$ на хромосорбе $W$, при $170^{\circ} \mathrm{C}$; газноситель - гелий, скорость 40 мл/мин.

Спектры ПМР снимали на приборе ZKР60 (рабочая частота 60 МГц) в виде $15 \%$-ного раствора в четыреххлористом углероде с ТМС в качестве внутреннего стандарта. Исходный телоген - 4-хлор-2-пентен получен по методике, описанной в [7]. Стирол $\left(d_{4}^{20} 0,9056, n_{D}^{20} 1,5466\right.$, чистота по ГЖХ 99,8\%) высушивали перегонкой в вакууме над металлическим натрием, метилстирол использовали в виде смеси $(3: 2)$ M- и $n$-изомеров ( $d_{4}^{20} 0,9849, n_{D}^{20} 1,5420$, чистота по ГЖХ 99,6\%). Реакция теломеризации проводилась по методике [7].

3-Метил-1-фенил-4-гексен-1-ол (III). 161 г (I) подвергали омылению $5 \%$-ным водным раствором бикарбоната натрия при температуре $10{ }^{\circ} \mathrm{C}$ в течение 100 ч. По окончании реакции органический слой извлекали петролейным эфиром и высушивали над прокаленным поташом. Петро- 
Химические сдвиги протонов 6-хлор-4-метил-6-фенил-2-гексена (I) и 6-хлор-4-метил-6-метилфенил-2-гексена (II)

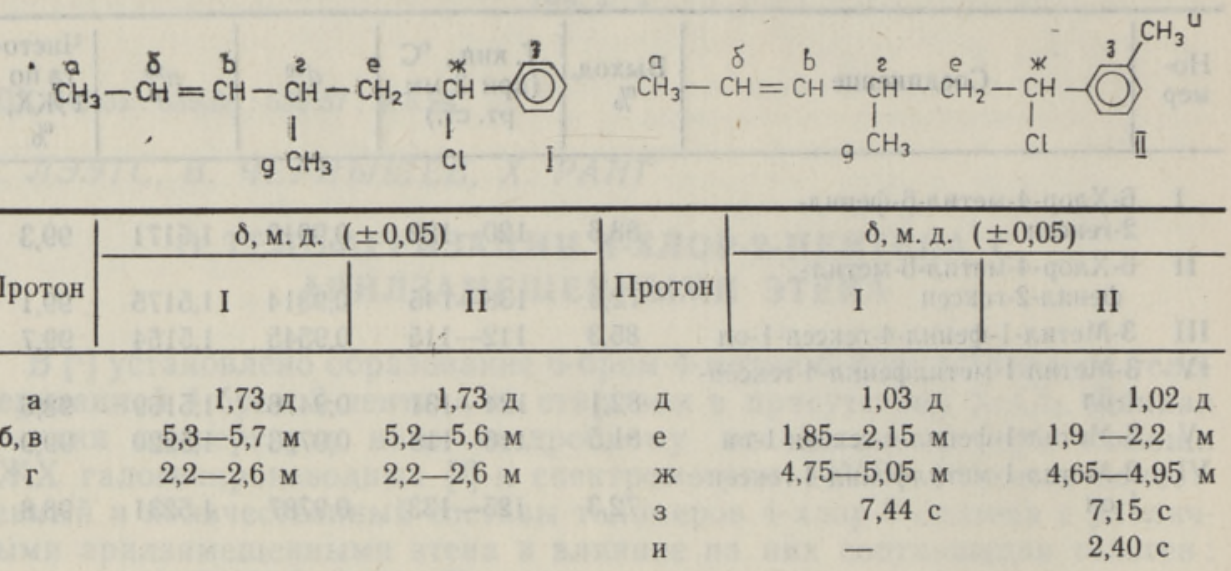

Химические сдвиги протонов 3-метил-1-фенил-4-гексен-1-ола (III) и 3-метил-1-метилфенил-4-гексен-1-ола (IV)

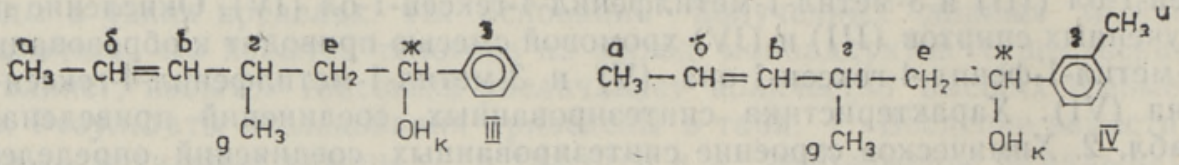

\begin{tabular}{c|c|c|c|c}
\hline \multirow{2}{*}{ Протон } & \multicolumn{2}{|c|}{ м. д. $( \pm 0,05)$} & Протон & І. м. д. $( \pm 0,05)$ \\
\cline { 2 - 4 } & III & IV & III \\
\hline
\end{tabular}

$\begin{array}{crrrlrr}\text { а } & 1,74 \text { д } & 1,71 \text { д } & \text { е } & 1,3-1,6 \mathrm{M} & 1,3-1,6 \mathrm{м} \\ 6, \text { в } & 5,35-5,7 \mathrm{M} & 5,35-5,7 \mathrm{M} & \text { ж } & 4,62 \mathrm{~K} & 4,63 \\ \text { г } & 2,2-2,6 \mathrm{M} & 2,2-2,6 \mathrm{M} & \text { 3 } & 7,32 \mathrm{c} & 7,22 \text { д } \\ \text { д } & 1,00 \text { д } & 0,98 \text { д } & \text { и } & - & 2,37 \mathrm{c} \\ & & & \text { к } & 2,80 \mathrm{c} & 2,93 \mathrm{c}\end{array}$

Химические сдвиги протонов 3-метил-1-фенил-4-гексен-1-она (V) и 3-метил-1-метилфенил-4-гексен-1-она (VI)

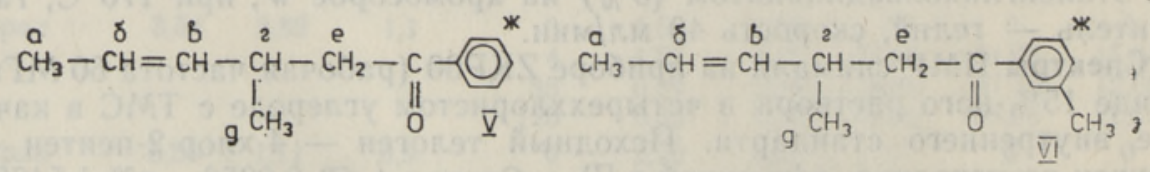

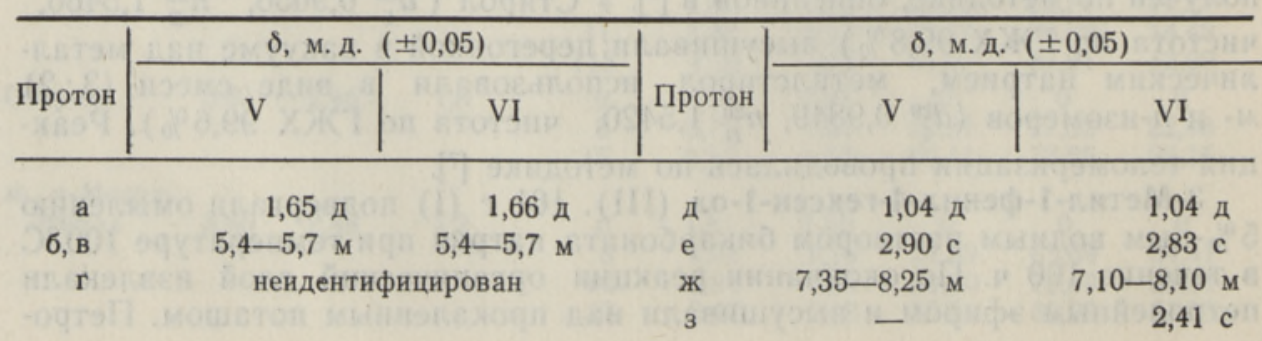


лейный эфир отгоняли в слабом вакууме. Получили 125,2 г сырого (III). Аналогично синтезировали спирт (IV).

3-Метил-1-фенил-4-гексен-1-он (V). К раствору 15 мл серной кислоты в 120 мл воды добавляли 24 г бихромата калия, а затем 18 г (III). Реакционную смесь перемешивали в течение 1 ч при $40-43{ }^{\circ} \mathrm{C}$ и обрабатывали водой. Органический слой промывали раствором соды, водой, высушивали сульфатом натрия и перегоняли в вакууме. Получили 14,4 г (V). Аналогично синтезировали кетон (VI).

\section{ЛИТЕРАТ У РА}

1. Черкасова Л. А., Бальян Х. В., Петров А. А. Присоединение гидробромида пиперилена к стиролу и фенилацетилену. - Ж. общ. хим., 1964, 34, 2926-2930.

2. Эрм А., Калья И., Лээтс К. Газовая хроматография галогенопроизводных аллильного типа. - Изв. АН ЭССР. Хим. Геол., 1972, 21, № 2, 300-304.

3. Бибичева А. И., Андреев В. М. Душистые вещества из продуктов алкилирования кетонов пренилхлоридом. І. 2-Метил-6-фенил-2-гексен-6-он и продукты его гидрирования. - Ж. орган. хим,. 1972, 8, № 7, 1389-1392.

4. Андреев В. М., Бибичева А. И., Журавлева М. Н. Душистые вещества из продуктов алкилирования кетонов пренилхлоридом. II. Алкилирование кетонов по методу Манкоши. - Ж. орган, хим., 1974, 10, № 7, 1470-1473.

5. Ранг Х. А., Чернышев В. О., Эрм А. Ю., Пехк Т. И., Лээтс К. В. З-Метил-1-фенилили 1-метилфенил-4-гексенолы и их ацетаты в качестве душистых веществ. Открытия, изобретения, 1979, № 34, 119, авт. свид. СССР № 685658.

6. Чернышев В. О., Ранг Х. А., Лээтс К. В. 3-Метил-1-фенил-4-гексен-1-оны в качестве душистых веществ. - Открытия, изобретения, 1980, № 10, 92, авт. свид. СССР № 721402 .

7. Чернышев В. О., Ранг Х. А., Пехк Т. И., Лээтс К. В. К изучению ионно-каталитической теломеризации. XIV. Теломеризация 2-хлор-транс-3-пентена с 1-пентеном. - Ж. орган. хим., 1977, 13, № 11, 2300-2304.

$\begin{array}{cc}\text { Институт химии } & \text { Поступнла в редакцию } \\ \text { Академии наук Эстонской ССР } & 19 / \mathrm{XI} 1987\end{array}$

K. LAATS, V. TSERNOSOV, H. RANG

\section{4-KLORO-2-PENTEENI TELOMERISATSIOON ARUULETEENIDEGA}

On käsitletud reaktsioonitingimuste ja taksogeeni struktuuri môju 4-kloro-2-penteeni ja arüületeenide telomeeride saagisele ja koostisele ning leitud, et metüülirühm benseeni tuumas vähendab monoaduktide saagist. Kloortelomeeridest on sünteesitud alkoholid ja ketoonid, mis on lōhnaained. Kōiki sünteesiprodukte on iseloomustatud PMR-spektriga.

\section{K. LAATS, V. CHERNYSHOV, H. RANG}

\section{ABOUT THE TELOMERIZATION REACTION OF 4-CHLORO-2-PENTENE WITH ARYLETENES}

The influence of the reaction conditions and the structure of taxogene on the yield and composition of telomerization products of 4-chloro-2-pentene with aryletenes has been investigated. The methyl group in the benzene ring decreases the yield of the primary telomerization adducts. The products obtained were used for synthesizing alcohols and ketones that are fragrance materials. All synthesized products are characterized by NMR spectra. 